\title{
PENGETAHUAN DAN SIKAP WANITA USIA SUBUR SEPUTAR MITOS KEHAMILAN DI KLINIK SULASTRI LAUT DENDANG TAHUN 2018
}

\author{
Debora Lestari Simamora \\ STIKes Imelda Medan, Indonesia
}

\section{Article Info}

Keywords:

Pregnancy

Fertile Age Women

\begin{abstract}
Pregnancy is a chain process that is continuous and consists of ovulation release of eggs, spermatozoa and ovum migration, conception and growth of the zygote, nidation (implantation) in the uterus, placental formation, and growth and development of the conception to the term (Manuaba, 2010). Myth is a story, opinion or assumption of a culture that is considered to have the truth about a case that was valid in the past, the truth is not necessarily true (Harry Lubis, 2009). Fertile Age women (WUS) are women whose reproductive organs function well between the ages of 20 and 45 years. This study aims to determine the knowledge and attitudes of women of childbearing age around pregnancy myths. The research design was accidental sampling with a sample size of 30 people. The study was conducted on 12 to 14 December 2018. The instrument in this study in the form of a questionnaire of research results can be seen that there are 17 respondents $(56.6 \%)$ do not agree with 5-10 myths on the questionnaire. A total of 13 respondents $(43.3 \%)$ still agreed $>5$ mythical questions on the questionnaire. From the results of the study found that there is still enough knowledge of women of childbearing age about the myths surrounding pregnancy.
\end{abstract}

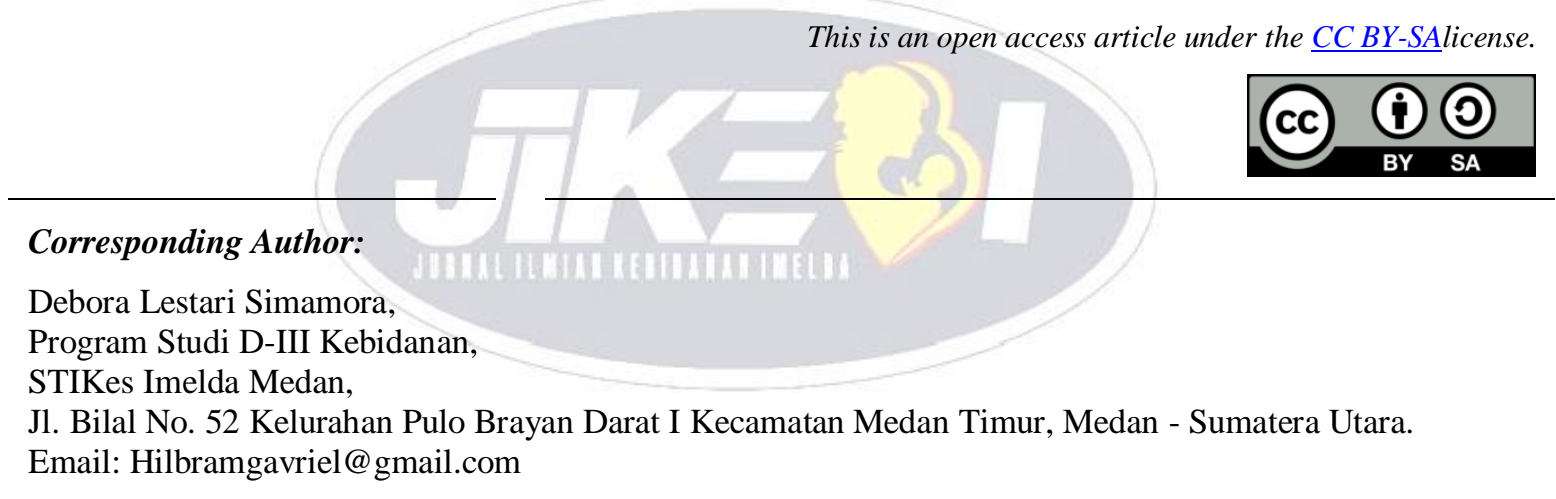

\section{INTRODUCTION}

Kehamilan merupakan suatu proses merantai yang berkesinambungan dan terdiri dari ovulasi pelepasan sel telur, migrasi spermatozoa dan ovum, konsepsi dan pertumbuhan zigot, nidasi (implantasi) pada uterus, pembentukan plasenta, dan tumbuh kembang hasil konsepsi sampai aterm (Manuaba, 2010).

Masa kehamilan dimulai dari konsepsi sampai lahirnya janin. Lamanya hamil normal adalah 280 hari (40 minggu atau 9 bulan 7 hari) dihitung dari haid pertama haid terakhir. Kehamilan dibagi dalam 3 triwulan pertama dimulai dari hasil konsepsi sampai 3 bulan, triwulan kedua dimulai dari bulan keempat sampai 6 bulan, triwulan ketiga dari bulan ketujuh sampai 9 bulan (Saifuddin, 2008; 89).

Data angka kematian ibu di Indonesia dari tahun ke tahun selalu terdapat kasus kematian ibu baik disebabkan oleh kehamilan ataupun persalinan. Berdasarkan data SDKI tahun 1991-2012, selama periode 
tahun 1991-2007 angka kematian ibu mengalami penurunan dari 390 menjadi 228 per 100.000 kelahiran hidup. AKI di Indonesia menurut Survei Demografi dan Kesehatan Indonesia (SDKI) tahun 2012 sebesar 359 per 100.000 kelahiran hidup, meningkat dibandingkan hasil SDKI tahun 2007 sebesar 228 per 100.000 kelahiran hidup. Sedangkan AKI di Jawa Tengah tahun 2012 berdasarkan laporan dari kabupaten/kota sebesar 116,34/100.000 kelahiran hidup, mengalami peningkatan bila dibandingkan dengan AKI pada tahun 2011 sebesar 116,01/100.000 kelahiran hidup. (DKK Provinsi Jawa Tengah, 2013).

Tenaga yang sejak dahulu kala sampai sekarang memegang peranan penting dalam pelayanan kebidanan ialah dukun bayi atau nama lainnya dukun beranak, dukun bersalin, dukun peraji. Dalam lingkungan dukun bayi merupakan tenaga terpercaya dalam segala soal yang terkait dengan reproduksi wanita. Ia selalu membantu pada masa kehamilan, mendampingi wanita saat bersalin, sampai persalinan selesai dan mengurus ibu dan bayinya dalam masa nifas. Dukun bayi biasanya seorang wanita sudah berumur \pm 40 tahun ke atas. Pekerjaan ini turun temurun dalam keluarga atau karena ia merasa mendapat panggilan tugas ini. Pengetahuan tentang fisiologis dan patologis dalam kehamilan, persalinan, serta nifas sangat terbatas oleh karena itu apabila timbul komplikasi ia tidak mampu untuk mengatasinya, bahkan tidak menyadari akibatnya, dukun tersebut menolong hanya berdasarkan pengalaman dan kurang professional (Prawirohardjo, 2005).

Mitos kehamilan yang terjadi pada ibu hamil dipengaruhi oleh berbagai faktor yang melingkupi setiap ibu hamil diantaranya adalah faktor pengetahuan. Faktor pengetahuan memegang peranan penting bagi ibu hamil dalam membentuk pola fikir dalam hal kepercayaan terhadap mitos. Semakin tinggi pengetahuan yang diperoleh oleh seseorang maka kepercayaan terhadap mitos makin diabaikan. Faktor keluarga juga berperan dalam kepercayaan terhadap mitos. Artinya bila pasangan suami istri tinggal bersama dengan orang tuanya maka banyak pantangan yang mesti mereka taati. Sebaliknya bila suami istri tinggal terpisah dengan orang tuanya mereka cenderung tidak mengikuti mitos tersebut. Alasannya karena tidak ada yang melarang dan mengingatkan. Selain itu faktor lingkungan hidup juga berpengaruh terhadap kepercayaan terhadap mitos. Maknanya, bagi masyarakat yang hidup didaerah yang dekat dengan pusat pelayanan kesehatan, mereka relatif lebih mudah melakukan interaksi dengan berbagai pengetahuan yang bersumber dari kesehatan modern (Barthes, 2007).

Di Indonesia ibu hamil tidak boleh makan nanas, durian, mentimun karena bisa mengakibatkan keputihan. Bahkan mereka percaya bahwa nanas bisa menyebabkan keguguran. Faktanya mengkonsumsi nanas, dan mentimun justru disarankan karena kaya akan vitamin $\mathrm{C}$ dan serat yang penting untuk menjaga kesehatan tubuh dan melancarkan proses pembuangan sisa-sisa 4 pencernaan (Lis sinsin, 2008). Berdasarkan dari latar belakang di atas, maka kami akan melakukan penelitian yang berjudul Pengetahuan Dan Sikap Wanita Usia Subur Seputar Mitos Kehamilan.

\section{RESEARCH METHOD}

Dalam penelitian ini penulis menggunakan rancangan cross sectional yaitu data yang terkumpul pada suatu waktu tertentu untuk memberikan gambaran perkembangan keadaan atau kegiatan pada waktu itu. Menurut sifatnya, penelitian ini termasuk jenis penelitian deskriptif, yaitu suatu metode penelitian yang mendeskripsikan atau menggambarkan suatu feomena yang terjadi didalam masyarakat atau menggambarkan masalah kesehatan serta yang terkait dengan kesehatan sekelompok penduduk atau orang yang tinggal dalam komunitas tertentu (Notoadmodjo, 2010). Penelitian ini dilakukan di Klinik Sulastri Am.Keb, Jl. Perhubungan Laut Dendang No.63, Kelurahan/Desa Laut Dendang, Percut Sei Tuan, Kabupaten Deli Serdang.

Populasi adalah keseluruhan subjek penelitian (Suharsini Arikunto, 2010). Populasi pada penelitian ini adalah wanita-wanita usia subur yang terdapat di sekitar Klinik Sulastri Am.Keb lebih tepatnya di Desa Laut Dendang yang berjumlah 30 orang. Sampel adalah sebagian atau wakil populasi yang diteliti (Suharsimi Arikunto, 2010). Sampel dalam penelitian ini adalah Wanita-wanita Usia Subur yang bertempat tinggal di sekitar Klinik Sulastri Am.Keb, lebih tepatnya di Desa Laut Dendang dengan menggunakan metode total sampling apabila subjeknya kurang dari 100, maka diambil semua (Arikunto, 2006). Dan menggunakan teknik Aksidental Sampling yaitu teknik penentuan sampel berdasarkan kebetulan, yaitu siapa saja yang secara kebetulan bertemu dengan peneliti dan bersedia sebagai sampel penelitian yaitu sebanyak 30 orang. Berdasarkan pendapat tersebut maka jumlah sampel yang dipakai peneliti adalah 30 Wanita Usia Subur.

\section{Instrumen Penelitian}

1. Metode Angket

Angket adalah suatu cara pengumpulan data atau suatu penelitian mengenai suatu masalah yang umumnya banyak menyangkut kepentingan umum (orang banyak). Angket dilakukan degan mengedarkan suatu daftar pertanyaan yang berupa formulir-formulir, diajukan secara tertulis kepada sejumlah subjek, dan instrumen yang digunakan adalah kuesioner. 
2. Teknik Pengukuran

Penilaian diukur dengan menggunakan kuesioner sikap yang berisi 10 pernyataan, dengan pilihan jawaban "Tidak Setuju"= 1 dan "Setuju"=0. Dan kuesioner pengetahuan yang berisi 10 pertanyaan, dengan jawaban "Benar"= 1 dan "Salah"= 0 . Skala pengukuran penilaian dalam penelitian ini menggunakan skala ordinal.

Data Primer adalah data yang dikumpulkan dan diolah sendiri oleh peneliti langsung dari subjek atau objek penelitian. Dalam penelitian ini, peneliti menggunakan Cara Pengumpulan Data Primer ini yaitu data yang diperoleh dari kuesioner yang diberikan kepada wanita-wanita usia subur yang terdapat di sekitar Klinik Sulastri Am.Keb lebih tepatnya di Desa Laut Dendang yang berjumlah 30 orang. Analisis data yang digunakan adalah analisis univariat yang dilakukan terhadap tiap variabel dari hasil penelitian. Pada umumnya analisis ini hanya menghasilkan distribusi dan persentase dari tiap variabel. Cara penyajian data dalam penelitian ini adalah dengan penyajian data dalam bentuk tabular (tabel) dan tekstular (narasi).

\section{RESULTS AND ANALYSIS}

Dari hasil penelitian yang dilakukan di Klinik Sulastri Am. Keb, Jl. Perhubungan Laut Dendang No.63, Kelurahan/Desa Laut Dendang, Percut Sei Tuan, Kabupaten Deli Serdang. Mengenai gambaran pengetahuan dan sikap wanita usia subur seputar mitos kehamilan seperti berikut:

Tabel 1. Distribusi Frekuensi Pengetahuan Dan Sikap Wanita Usia Subur Seputar Mitos Kehamilan Di Klinik Sulastri Am. Keb 2018 Berdasarkan Umur, Dan Pendidikan

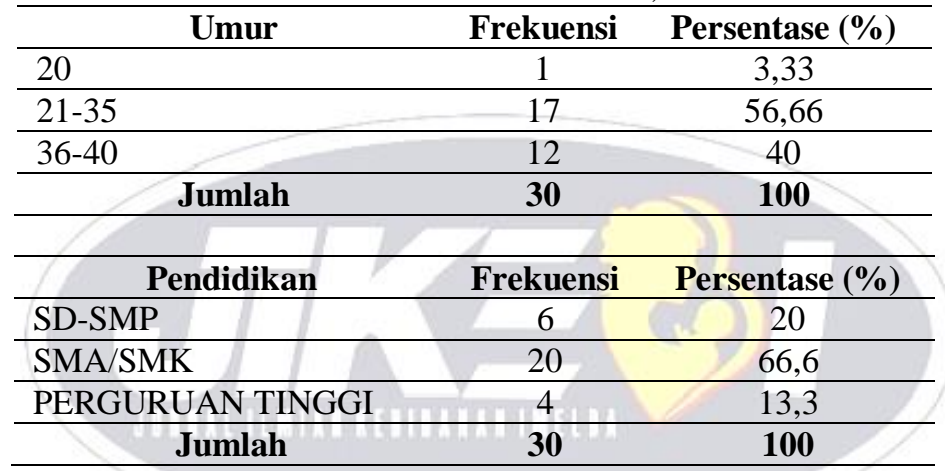

Berdasarkan dari tabel di atas dapat kita lihat perilaku Umur, sebanyak 1 orang $(3,33 \%)$ di jumpai umur 20 tahun, Sebanyak 17 Orang (56,66\%) di jumpai umur 21-35 tahun, dan 12 orang (40\%) umur 36-40 tahun. Berdasarkan dari tabel diatas dapat dilihat responden yang berpendidikan SD-SMP dijumpai sebanyak 6 orang (20\%), SMA/SMK Sebanyak 20 orang (66,6\%), PERGURUAN TINGGI sebanyak 4 orang $(13,3 \%)$.

Tabel 2. Distribusi Frekuensi Pengetahuan Wanita Usia Subur Seputar Mitos Kehamilan Di Klinik Sulastri Am. Keb 2018

\begin{tabular}{lccc}
\hline Pengetahuan & Nilai & Frekuensi & Persentase (\%) \\
\hline Baik & $8-10$ & 25 & 83,3 \\
\hline Cukup & $5-7$ & 5 & 16,6 \\
\hline Kurang & $<5$ & 0 & 0 \\
\hline \multicolumn{1}{c}{ Total } & $\mathbf{1 0}$ & $\mathbf{3 0}$ & $\mathbf{1 0 0}$
\end{tabular}

Berdasarkan tabel diatas menunjukkan bahwa distribusi pengetahuan wanita usia subur seputar mitos kehamilan di klinik sulastri 2018 dari 30 responden yang telah di teliti, mayoritas Baik yaitu yang menjawab pertanyaan benar sebanyak 8-10 pertanyaan sebanyak 25 orang responden (83,3\%). Minoritas Cukup yaitu yang menjawab benar hanya 5-7 pertanyaan sebanyak 5 orang responden (16,6\%). Dan tidak ada responden yang berpengetahuan kurang atau yang hanya benar dibawah 5 pertanyaan.

Tabel 3. Distribusi Frekuensi Sikap Wanita Usia Subur Seputar Mitos Kehamilan Di Klinik Sulastri Am. Keb 2018

\begin{tabular}{lccc}
\hline Pengetahuan & Nilai & Frekuensi & Persentase (\%) \\
\hline Baik & $8-10$ & 3 & 10 \\
\hline Cukup & $5-7$ & 14 & 46,66 \\
\hline Kurang & $<5$ & 13 & 43,3 \\
\hline \multicolumn{1}{c}{ Total } & $\mathbf{1 0}$ & $\mathbf{3 0}$ & $\mathbf{1 0 0}$ \\
\hline
\end{tabular}


Berdasarkan tabel diatas menunjukkan bahwa distribusi sikap wanita usia subur seputar mitos kehamilan di klinik sulastri 2018 dari 30 responden yang telah di teliti, mayoritas Cukup yaitu yang menjawab Tidak Setuju 5-7 pernyataan mitos sebanyak 14 orang responden (46,66\%). Responden yang bersikap Kurang yaitu yang menjawab Tidak Setuju $<5$ pernyataan mitos sebanyak 13 orang responden $(43,3 \%)$. Dan minoritas Baik yaitu yang menjawab Tidak Setuju 8-10 pernyataan mitos atau sama sekali tidak mempercayai mitos seputar kehamilan hanya sebanyak 3 orang responden (10\%) saja.

\section{CONCLUSION}

Setelah dilakukan penelitian mengenai "Pengetahuan Dan Sikap Wanita Usia Subur Seputar Mitos Kehamilan Di Klinik Sulastri Am. Keb Tahun 2018”, dapat disimpulkan bahwa pengetahuan dan sikap wanita usia subur seputar mitos kehamilan dalam hal ini dipengaruhi oleh beberapa faktor seperti: Pendidikan dan Umur. Faktor-faktor tersebut sangat menentukan pengetahuan dan sikap wanita usia subur seputar mitos kehamilan, yaitu:

a. Frekuensi pengetahuan wanita usia subur seputar mitos kehamilan berdasarkan Umur mayoritas berpengetahuan Baik pada usia 20-35 tahun sebanyak 25 orang responden $(83,3 \%)$, dan minoritas berpengetahuan Cukup pada usia 35-40 tahun sebanyak 5 orang (16,6\%). Berdasarkan asumsi penelitian, semakin muda usia responden maka semakin tinggi pengetahuan responden terhadap hal hal yang baik dilakukan selama masa kehamilan.

b. Frekuensi sikap wanita usia subur seputar mitos kehamilan berdasarkan Pendidikan mayoritas bersikap Cukup yaitu yang berpendidikan SMA/SMK dan satu responden yang berpendidikan PERGURUAN TINGGI sebanyak 14 orang responden $(46,66 \%)$ dan minoritas bersikap Baik atau yang sama sekali tidak mempercayai mitos mitos seputar kehamilan yaitu yang berpendidikan PERGURUAN TINGGI sebanyak 3 orang responden (10\%). Dan yang masih mempercayai mitos seputar kehamilan masih cukup banyak yaitu yang berpendidikan SD-SMP dan sebagian yang berpendidikan SMA/SMK sebanyak 13 orang responden $(43,3 \%)$. Berdasarkan asumsi penelitian, semakin tinggi pendidikan responden maka semakin baik sikap responden dalam menghadapi mitos mitos yang sebenarnya belum tentu terbukti kebenarannya. Namun dalam penelitian ini peneliti menemukan bahwa yang berpendidikan SMA pun masih cukup banyak yang mempercayai mitos mitos seputar kehamilan dikarenakan responden masih mengikuti ajaran yang masih mempercayai mitos atau para ibu mertua dari responden tersebut.

\section{REFERENCES}

Kartikowati, S. dan Ahmad Hidin. (2014). Sistem Kepercayaan di Kalangan Ibu Hamil Dalam Masyarakat Melayu. Parallela. 1(2). 89-167.

Kasnodiharjo, dan Lusi Kristiana. (2013). Praktek Budaya Perawatan Kehamilan di Desa Gadingsari Yogyakarta. Kesehatan Reproduksi. 3(3). 113-123.

Khoililurrohman. (2003). Hubungan Antara Kepercayaan Terhadap Mitos Kehamilan Dengan Perilaku Kehati-Hatian Menjelang Persalinan. Yogyakarta: Psikologi UGM.

Prawirohardjo, Sarwono. (2013). Ilmu Kebidanan. Jakarta: Bina Pustaka Sarwono Prawirohardjo.

Sulistyawati, Ari. (2009). Mitos kehamilan. Yogyakarta.

Tiyantiyanti. (2014). Pengaruh Mitos Seputar Kehamilan. Jakarta.

Wiknjosastro, Hanifa. (2006). Pengetahuan Ibu Hamil Tentang Mitos Kehamilan. Jakarta: Yayasan Bina PustakaSarwono Prawirohardjo.

\section{BIOGRAPHIES OF AUTHORS}

\begin{tabular}{|l|l|}
\hline Debora Lestari Simamora, Gelar D-III diperoleh dari Akademi Kebidanan Imelda \\
Medan, Jurusan Kebidanan pada tahun 2009. Gelar Sarjana diperoleh dari Poltekes \\
Kemenkes RI Medan, Jurusan Bidan Pendidik Tahun 2011. Magister Kesehatan \\
diperoleh dari Universitas Sumatera Utara, Jurusan Kesehatan Reproduksi pada tahun \\
2017. Saat ini aktif sebagai dosen tetap di Prodi D-III Kebidanan STIKes Imelda \\
Medan.
\end{tabular}

